\title{
Realistic Claims in Logical Empiricism
}

\author{
Matthias Neuber
}

Logical empiricism is commonly seen as a counter-position to scientific realism. In the present paper it is shown that there indeed existed a realist faction within the logical empiricist movement. In particular, I shall point out that at least four types of realistic arguments can be distinguished within this faction: Reichenbach's 'probabilistic argument,' Feigl's 'pragmatic argument,' Hempel's 'indispensability argument,' and Kaila's 'invariantist argument.' All these variations of arguments are intended to prevent the logical empiricist agenda from the shortcomings of radical positivism, instrumentalism, and other forms of scientific antirealism. On the whole, it will be seen that logical empiricism and scientific realism are essentially compatible with each other. Especially Kaila's invariantist approach to science (and nature) comes quite close to what nowadays is discussed under the label 'structural realism.' This, in turn, necessitates a fundamental reevaluation of Kaila's role in the logical empiricist movement in particular and in twentieth-century philosophy of science in general.

Keywords: logical empiricism, structural realism, semantics, invariance, Eino Kaila

\section{Introduction}

Logical Empiricism has for a long time been conceived of as a monolithic, one-dimensional, movement within early twentieth-century philosophy. As such, it frequently served as a contrast for later, opposing viewpoints, such as scientific realism, critical rationalism, or Kuhnian historical relativism. However, as more recent research has revealed, logical empiricism was much more multifaceted than commonly assumed. Especially the seminal contributions by Michael Friedman (1999), Friedrich Stadler (2001), and Thomas Uebel (2007) strongly indi- 
cate that the assumption of the existence of varieties of logical empiricism is clearly closer to the truth than the view of it as a narrow, quasi-dogmatic 'school.'

As concerns the debate over scientific realism, appraisals like the following, suggesting a strong incompatibility between scientific realism and logical empiricism, are still quite widespread:

The philosophy of science in the twentieth century has been a battlefield between 'realist' and 'anti-realist' approaches. The interpretation of scientific theories, and the dispute about the cognitive significance of their theoretical terms and claims, provided a major impetus for the work of the Vienna Circle in the 1920s. The demise of logical positivism was followed by the rise of scientific realism within the analytic philosophy of science in the 1950s [...]. (Niiniluoto 1996, p. v)

There is little doubt that scientific realism became the dominant position in the philosophy of science in the second half of the twentieth century. And it cannot be denied that logical empiricism began to lose momentum. However, it must be seen that the logical empiricist program - at least in some of its guises - was not so different from the scientific realist account of science and nature. To be sure, there was a strong rejection of any form of metaphysical realism. But with respect to empirical science, most of the logical empiricists regarded realism not as a particularly contentious issue. Rather, they attempted to argue for the case of realism. More precisely, four kinds of arguments can be distinguished in this connection: a 'probabilistic argument,' a 'pragmatic argument,' an 'indispensability argument,' and an 'invariantist argument.' Given the variety of arguments, it is plausible to assume that logical empiricism and scientific realism are essentially compatible with each other.

It is the aim of the following considerations to clarify and fortify this compatibilist idea of 'realistic claims in logical empiricism.' I will attempt to make clear that the logical empiricists from the very beginning were rather open-minded toward an empirical, non-speculative, understanding of realism (Section 2). My goal is to demonstrate that this sort of programmatic open-mindedness developed into a (more or less) sophisticated commitment to the scientific realist agenda (Section 3) and that one specific articulation of 'realistic claims in logical empiricism,' namely the one delivered by Eino Kaila, comes close to current 'structural' realism (Section 4). By way of conclusion, it will be suggested that Kaila's (invariantist) approach gives rise to the establishment of an autonomous, measurement-based, account of structural realism (Section 5). 


\section{The Realism Issue: A Mere Pseudo-Problem?}

To help clarify the idea of 'realistic claims in logical empiricism,' it is reasonable to begin with what might be called the 'received view' of the logical empiricist approach toward the realism issue. According to this received view, the realism issue is nothing but a pseudoproblem. And indeed: By examining the relevant writings of the relevant authors, one pretty soon discovers that the received view can easily be corroborated. Thus, for example, Rudolf Carnap, in his Pseudoproblems in Philosophy from 1928, explicitly states: "In the realism controversy, science can take neither an affirmative nor a negative position since the question has no meaning." (Carnap [1928a] 1968, p. 333) Quite similarly, Moritz Schlick, in his 1932 essay "Positivism and Realism," argued that realism has no place in science because "the 'problem of the reality of the external world' is a meaningless pseudo-problem" (Schlick [1932] 1979, p. 263). Thus, both Carnap and Schlick banished the realism issue from the field of meaningful questions.

However, one must be careful to not overgeneralize this estimation. To be sure, the characterization of the realism issue as a pseudo-problem forms one of the building blocks of the logical empiricist critique of metaphysics (see Friedman 2007 and Creath 2014). Yet it must be taken into account that both Carnap and Schlick, while rejecting metaphysical realism, emphatically argued for a non-speculative, empirical, realism. More precisely, both Carnap and Schlick thought of the outer-world hypothesis (the hypothesis of objects existing independently of our consciousness) as meaningless. At the same time, though, they welcomed a realistic interpretation of the empirical statements of science. Thus, Carnap, in his The Logical Structure of the World (first published in 1928), points out:

The realistic language, which the empirical sciences generally use, and the constructional language have actually the same meaning: they are both neutral as far as the decision of the metaphysical problem of reality between realism and idealism is concerned. It must be admitted that, in practice, linguistic realism [sprachlicher Realismus], which is very useful in the empirical sciences, is frequently extended to a metaphysical realism; but this is a transgression of the boundaries of science [...]. (Carnap [1928b] 1968, pp. 86-87)

In a similar vein, Schlick in "Positivism and Realism" argued that positivism and realism are "not opposed" ([1932] 1979, p. 283) as long as the limits of experience are not transgressed. He even went so far as to contend that anyone who acknowledges the logical empiricist verification principle "must actually be an empirical realist" (ibid.). 
Given these qualifications, it remains a largely open question what exactly was implied by the sort of empirical realism proposed by Carnap and Schlick. Certainly, for Schlick, empirical realism has to be understood in Kantian terms (see Schlick [1932] 1979, Sect. III). However, according to Kant himself, empirical realism is dependent on transcendental idealism and thus quite far away from both scientific realism and logical empiricism (see in this regard also Neuber 2014). Be that as it may, the important point to notice is that neither Carnap nor Schlick rejected realism unreservedly. Their rejection was confined to metaphysical realism, leaving enough space for accepting the raison d'être of a realistic interpretation of the language of science.

\section{Realism as a Problem of Language}

The work of spelling out this sort of interpretation, though, was left to others. The first one to be mentioned in this connection is Hans Reichenbach who, in his seminal Experience and Prediction from 1938, elaborated on the idea that the language of science be interpreted in realistic terms. Reichenbach's frame for designing such a scientific realist account was the theory of meaning, i.e., semantics. What he proposed was a "probability theory of meaning" (see Reichenbach 1938, §7), which he thought was strong enough to incorporate a semantics for theoretical terms, such as 'atom,' 'electromagnetic field,' etc. (see ibid., § 25)

Reichenbach's conception has been subject of extended investigation by various scholars (see, for example, Salmon 1999a, Putnam 2001, Psillos 2011a, Sober 2011). The crucial point in this conception is the assumption of a surplus meaning of theoretical terms. That is, in Reichenbach's view the meaning of theoretical terms is not exhausted by their being reducible to an observational evidence base. Rather, they are invested with an autonomous dimension of explanatory impact, which, Reichenbach maintained, could be elegantly captured by a probabilistic theory of inductive inference. More precisely, Reichenbach - in the context of his famous 'cubical world' analogy (see Reichenbach 1938, § 14) - pointed out that the existence of theoretical ('unobservable') entities can be inferred inductively by searching for the causes of (regularly occurring) observable effects (like, for example, the tracks in a Wilson cloud chamber). The inferred entities, which Reichenbach called "illata" (see ibid., p. 212), had the status of independently existing things, and their relation to immediately observable entities Reichenbach called them "concreta" (ibid.) - was that of a "probability connection." Or, as Reichenbach explained by referring to the example of atoms: 
Since all observable qualities of the macroscopic bodies are only averages of qualities of the atoms, there are no strict inferences from the macroscopic bodies to the atom but only probability inferences; we have, therefore, no equivalence between statements about the macroscopic body and statements about the atoms but only a probability connection. (ibid., p. 216)

All of this suggests a strong commitment to the scientific realist agenda. Relying on the specification of the basic scientific realist theses, as it has been provided by Stathis Psillos in his Scientific Realism: How Science Tracks Truth (see Psillos 1999, pp. xix-xxi), Reichenbach's position might be summarized as follows: On the ontological level, the independent existence of theoretical entities (such as atoms) is assumed; on the semantic level, we have a theory of meaning for theoretical terms, namely the probability theory of meaning; on the epistemological level, it is assumed that theoretical entities (and their causal properties) are inductively accessible. In short, Reichenbach endorsed all of the central features of modern scientific realism.

However, there are problems lurking in the background. The most obvious of these problems has to do with Reichenbach's interpretation of probability. As is well known, Reichenbach in Experience and Prediction defended a frequency interpretation of probability (see Reichenbach 1938, $\S 32$ and 38). Yet it is by no means clear how by invoking frequencies of observable events ('objective probabilities') the inference to unobservable entities like atoms could be justified. Reichenbach's logical empiricist fellow Herbert Feigl made exactly this point, arguing that

[t]he crux of the problem lies in the justification of applying the concept of inductive probability to the inference from the directly verifiable to directly unverifiable assertions. Any straightforward frequency interpretation of probability could serve here only if the success frequencies of such inferences were ascertainable. This is outright impossible if independent access to the "Illata" is barred. [...] [T]he legitimacy of applying the probability concept to the whole realistic frame, instead of merely to inferences within it, remains painfully questionable. (Feigl 1950a, p. 53)

The same objection had already been raised by Ernest Nagel (see Nagel 1938, p. 271 and Nagel 1939, p. 237-38). It essentially amounts to the observation that the realistic framework must already be in place in order to make inductive inferences to unobservable entities work. Accordingly, Reichenbach's probability theory of meaning "requires the realist framework and cannot be a proof of it" (Psillos 2011a, p. 37). 
This is, however, not the proper forum to examine how Reichenbach's argument for scientific realism could be improved by modifying his account of probability (for an interesting attempt, see Sober 2011). Nor is it my concern to dwell on Reichenbach's later work and on his famous "principle of the common cause" (see in this connection Reichenbach 1956 and the reconstruction in Salmon 2005, pp. 24-25). What should be kept in mind, however, is that the 'probabilistic argument' brought forward in Experience and Prediction should be seen as a forerunner of more recent - 'naturalistic' - conceptions of the scientific realistic approach (see in this connection, for example, Boyd 1982 \& 1983 and Salmon 1984). This is not to say that Reichenbach's probabilistic argument is beyond debate (for a critical discussion, see Psillos 2011a). But it seems to be clear that by focusing on the concept of probability Reichenbach paved the way for mid- and late twentieth-century articulations of the scientific realist agenda.

However, as already indicated, the probabilistic argument cannot be further discussed in this paper. Rather, I wish to take a closer look at Herbert Feigl's approach toward the realism issue, as he outlined it in his essay "Existential Hypotheses: Realistic versus Phenomenalistic Interpretations" (first published in 1950). It is no exaggeration to state that this essay was Feigl's most important contribution to the debate over realism. In its essence, it contained a (language-based) 'pragmatic argument' which must be strictly distinguished from Reichenbach's probabilistic argument.

To begin with, like Reichenbach, Feigl intended to provide us with an affirmative (or constructive) treatment of the realist idea. Furthermore, Feigl, again like Reichenbach, based his argumentation on semantics. By taking semantics seriously, he maintained, "[t]he glib and easy dismissal of the issue as a pseudo-problem will no longer do" (Feigl 1950a, p. 36). Accordingly, what Feigl basically intended was, as he claimed, a "rapprochement" between a "critical phenomenalism (or operationism)," on the one hand, and a "critical (or empirical) scientific realism," on the other (ibid., p. 41). Feigl called the resulting position "Semantic Realism" (ibid., p. 50) and demarcated it from what he called "Probabilistic Realism" (ibid., p. 52). The latter point of view was, as Feigl explicitly remarked, the one defended, among others, by Reichenbach (see ibid., p. 45). As already pointed out, Feigl refused Reichenbach's frequentist interpretation of probability. More generally, he repudiated the entire probabilistic approach. According to Feigl, scientific realism with its "existential hypotheses" concerning theoretical entities could not be justified inductively. Quite the other way round: 
the conceptual frame of the realistic language by its entailed consequence; viz. by showing that only within such a frame it makes sense to assign probabilities to existential hypotheses. (ibid., p. 54)

Thus, in Feigl's view, we first have to establish the realist framework and we then are in a position to raise questions about the probability of specific existential hypotheses concerning theoretical entities. Or, as he argued at another place:

The customary probabilistic realism in trying to justify "transcendent" hypotheses on the basis of experimental findings has put the cart before the horse. Only after the introduction of the realistic frame can we legitimately argue inductively either from the theory to the outcome of as yet unperformed experiments; or vice versa from the results of experiments to specific postulates of the theory. (Feigl 1950b, p. 195)

Thus, according to Feigl, it is "the presupposed introduction of the realistic frame, i.e. the semantic-realistic interpretation of the theory" which "furnishes the very possibility of a theory that is inductively fruitful" (ibid.).

But how, then, can the adoption of the realist framework itself be motivated? As Psillos has correctly observed, answering this question from the perspective of Feigl "is, ultimately, a matter of convention" (Psillos 2011b, p. 308). That is, for Feigl, realism is dependent on a foregoing conventionalist decision. Consequently, realism cannot be justified naturalistically, but only in a quasi-transcendental manner. By 'quasi-transcendental' I mean the assumption that we cannot directly refer to theoretical (unobservable) entities but that we first have to reflect on the 'conditions of the possibility' of drawing inductive-probabilistic inferences. As in the case of Feigl, this assumption is only quasi-transcendental because it is not related to (truth-conducive) statements but only to (action- and decision-relevant) conventions and thus rather 'regulative' than 'constitutive' in the original Kantian sense. As such, it serves as the basis of an essentially pragmatic argument. Or, in Feigl's own words:

The introduction of new basic and irreducible concepts (as, for example, in electromagnetics during the last century) may be reconstructed as an expansion of the empirical language. Only after our language has thus been enriched, can we significantly assign probabilities (degrees of confirmation) to specific predictive or explanatory hypotheses. The step of expansion of language cannot itself be justified on the grounds of probability, except perhaps in the sophisticated pragmatic sense of the question: Will this expansion be methodologically fruitful? (Feigl 1950a, p. 57) 
After all, it is the insight in the "need for definitional or conventional stipulation" (ibid., p. 54) by which, according to Feigl, the realist enterprise is motivated in the first place. The 'condition of the possibility' of the realist program lies outside the reach of the realist program itself. Or as Psillos has aptly put it, for Feigl, there is "no ultimate argument for the adoption of the realist framework" (Psillos 2011b, p. 303). Ontic questions are pragmatic "frameworkquestions" (ibid.), and framework-questions must be decided by convention before any specific existential hypothesis concerning theoretical entities can be evaluated.

The problematic aspects of this quasi-transcendental, convention-based, justification of scientific realism have been discussed elsewhere (see Neuber 2011 \& 2014). To put it in a nutshell, Feigl's approach seems not to go beyond the later Carnap's ontological 'neutralism' (see Carnap 1956 [1950]). On the other hand, it must be seen that Feigl's contribution formed an autonomous variety of 'realistic claims in logical empiricism.' Especially his contention that theoretical terms have "factual reference" (Feigl 1950a, p. 48) distinguished his "semantic realism' as a remarkable deviation from early, verificationist, accounts of logical empiricism. However, as Carl Gustav Hempel (1950, pp. 172-73) pointed out in his critique of Feigl's view, the very conception of factual reference fell victim to other restrictions within the logical empiricist agenda. After all, Feigl's semantic realism boiled down to the charge that theoretical statements be "indirectly confirmable" (Feigl 1950a, p. 57). Their 'factuality' was tied to directly confirmable observation statements, the systematic function of which, Feigl maintained, provided "a maximum of nomological coherence by means of a minimum of hypothetical construction" (ibid.). No doubt that an instrumentalist (or operationist) would have embraced this point of view, all the more since Feigl repeatedly claimed that the realist frame itself was nothing but a "basic convention" (ibid.) that could be "justified only instrumentally" (Feigl 1950b, p. 195). It was for this reason that Hempel did, as he concluded, "not feel convinced that reliance on the problematic concept of the factual referents of theoretical constructs is necessary or even helpful in an attempt to achieve a comprehensive and coherent theoretical account of scientific method and scientific knowledge" (Hempel 1950, p. 173). In fact, also at a larger scale Feigl's plea for scientific realism did not come to fruition. The 'pragmatic argument' he offered could hardly convince the philosophy of science community (for the details of this diagnosis, see Neuber 2011; for a recent vindication of Feigl's pragmatic argument, see Psillos 2011b).

Hempel's critique of Feigl's interpretation of the status of theoretical concepts formed the point of departure for a third variety of 'realistic claims in logical empiricism.' In his guiding paper "The Theoretician's Dilemma: A Study in the Logic of Theory Construction," first pub- 
lished in 1958, Hempel focused on the purpose of scientific theory construction. As he saw it, the principle aim of building theories was "systematization." Conceiving of theories as axiomatized systems (see Hempel 1958, p. 46), Hempel confronted the reader with the following straightforwardly anti-realist - line of reasoning:

If the terms and principles of a theory serve their purpose they are unnecessary, as just pointed out, and if they don't serve their purpose they are surely unnecessary. But given any theory, its terms and principles either serve their purpose or they don't. Hence, the terms and principles of any theory are unnecessary. (ibid., pp. 49-50)

This argument is called by Hempel the theoretician's dilemma (ibid., p. 50). However, it must be said that the dilemma's second horn is trivial, while the first horn of the dilemma is in need of comment. It seems to represent the view of the 'sophisticated' anti-realist. Thus, it could be agreed upon that theoretical concepts and statements serve their purpose if they establish nomological connections among observable phenomena. But then, the sophisticated anti-realist could argue, theoretical concepts and statements can be dispensed with since they are replaceable by concepts and statements that directly refer to the realm of observable phenomena. Logical techniques such as Craig's theorem or the Ramsey-sentence apparently substantiate this abstract claim (see ibid., Sect. 9).

It is not very difficult to see that Feigl's account of scientific realism is suspiciously close to the sophisticated anti-realist's conception. No wonder, then, that Hempel rejected Feigl's point of view as unconvincing. But what was his alternative? As Hempel comprehensively points out in "The Theoretician's Dilemma," one must distinguish between two types of systematization: deductive and inductive systematization. While in the context of deductive systematization theoretical terms are dispensable, they are indispensable for the purposes of inductive systematization. According to Hempel, theories are partially interpreted systems, i.e., systems of concepts and statements that cannot be entirely reduced to the observational evidence base. He therefore is convinced that "the Ramsey-sentence associated with an interpreted theory T' avoids reference to hypothetical entities only in letter - replacing Latin constants by Greek variables - rather than in spirit" (ibid., p. 81). In fact, Hempel maintains, "Ramseysentences provide no satisfactory way of avoiding theoretical concepts" (ibid.). This comes as no surprise, since it is theoretical concepts that are needed for the sake of inductive systematization. However, as Hempel argues in direct contradistinction to Feigl, "semantics does not enable us to decide whether the theoretical terms in a given system T' do, or do not, have semantical, factual, or ontological reference" (ibid., p. 82: my emphasis). From a purely seman- 
tic point of view, the referent of any term can be specified, given that our metalanguage is rich enough. Therefore, Hempel concludes, "we have to look elsewhere for criteria of significance for theoretical terms and sentences" (ibid.)

What are these criteria? According to Hempel, we just have to know the rules by which sentences of the basic observational vocabulary, $\mathrm{V}_{\mathrm{B}}$, are inferred from sentences containing theoretical terms. This exactly is provided by the procedure of partial interpretation, and we thereby at the same time obtain a workable conception of how inductive relations are established among observable phenomena Thus, given a theoretical hypothesis $\mathrm{H}_{\mathrm{T}}$ entails observational consequences $\mathrm{OC}_{1}, \mathrm{OC}_{2}, \ldots, \mathrm{OC}_{\mathrm{n}}$, we can inductively infer that $\mathrm{H}_{\mathrm{T}}$ is true. Further, given that $\mathrm{H}_{\mathrm{T}}$ entails a new confirmable prediction $\mathrm{OC}_{\mathrm{n}+1}$, we are obviously entitled to conclude that $\mathrm{H}_{\mathrm{T}}$ is indispensable because the derivation of $\mathrm{OC}_{\mathrm{n}+1}$ rests - in an essential way - on the assumption that the inductively obtained hypothesis $\mathrm{H}_{\mathrm{T}}$ is true. This is Hempel's way out of the theoretician's dilemma. He claims to have convincingly shown that it starts with a false premise, namely that theoretical terms and sentences, if they serve their purpose, are unnecessary (see ibid., p. 87). Accordingly, for Hempel, a realist interpretation of science is justified. Theoretical systems can, on that basis, be regarded as significant, and the factual reference of theoretical terms can be captured by the following deflationist account of truth: "To assert that the terms of a given theory have factual reference, that the entities they purport to refer to actually exist, is tantamount to asserting that what the theory tells us is true; and this in turn is tantamount to asserting the theory." (ibid., p. 84) Thus, when we assert that the elementary particles of contemporary physical theory exist, we assert the truth of the (partially interpreted) physical theory of elementary particles. Moreover, Hempel maintains that on his account the basic tenets of empiricist philosophy can be kept up. In particular, he is eager to tie the theoretical vocabulary to the basic observational vocabulary. The factual reference of theoretical terms is, in Hempel's view, straightforwardly implied by the theory's being true, and the theory's being true can be determined by "an empirical investigation of its $\mathrm{V}_{\mathrm{B}}$-consequences" (ibid., p. 85)

It is hard to see why Hempel's approach should mark a step beyond the point of view defended by Feigl. To be sure, the insight in the indispensability of theoretical terms is a necessary condition for holding a realist position in the philosophy of science. But the 'indispensability argument' as such is by no means sufficient. Scientific anti-realists could concede the indispensability of theoretical terms but at the same time deny their factual reference. They could, in other words, admit that theoretical terms are necessarily needed for the sake of inductive systematization, but (without becoming bogged down in contradictions) contend that 
their function is exhausted by this purely systematizing role. That is to say, what is missing in Hempel's approach is an independent argument for the claim that theoretical terms factually refer to (independently existing) theoretical entities. Without such an additional argument, Hempel's conception remains open for non-realist reformulations in the spirit of the later Carnap's 'external/internal questions'-point of view (for a fuller discussion of this see Salmon 1999b, pp. 336-37 and Salmon 2005, pp. 26-28).

\section{The Invariantist Alternative}

By making the factual reference of theoretical terms derivative from theoretical truth, Hempel remains, despite his own contention, within the realm of semantics and thereby within the interpretation of the realism issue as a problem of language. Like Feigl, he finally ends up with a severe empiricist restriction: theoretical truths - and with them theoretical terms - must be essentially tied to the foundation of observational evidence. But why then is this argument operating along realist lines? Would it not suffice to focus on the observational (experimental) adequacy of scientific theories? Or, as Ernest Nagel put it in his critique of Feigl's "Existential Hypotheses:"

[W]hether one assumes existential hypotheses to be translatable into the language of direct observation, or construes them as elements in a complex symbolic apparatus whose function is to establish systematic relations between experimental data, in either case it seems quite intelligible to assert that a hypothesis is in agreement with a given body of evidence to some specified extent. (Nagel 1950, p. 181)

Why, then, should logical empiricists allow for a realist reading of science at all?

A possible answer to this question is that such a realist reading is demanded by science itself. In a certain sense, among the logical empiricists it was Reichenbach who, by invoking the concept of probability, initiated such a non-transcendental, naturalistic, approach to science and scientific theory construction. However, the one who articulated this approach most potently was (at least in my opinion) Eino Kaila. According to Kaila, the realism issue is definitely not a problem of language. In his view, the problems of philosophy concern, ultimately, scientifically described reality rather than (the quasi-transcendental) questions of 'language engineering.' Thus, as early on as in 1930, in his Logistic Neopositivism (a critique particularly of Carnap's Aufbau), Kaila declares that "the 'realist language' of science is actually far more than a mere manner of speaking: it is the expression of the living soul of science" (Kaila 
[1930] 1979, p. 4). To be sure, this could be interpreted as the articulation of (a certain variant of) 'bad metaphysics.' However, what Kaila intends to clarify is that a mere reflection on the language of science is not enough in order to account for the empirical content of scientific theories. In other words, according to Kaila it is impossible - or, better, irresponsible - to ignore the 'material mode of speaking' (inhaltliche Redeweise) and to restrict philosophical analysis to the 'formal mode of speaking' (formale Redeweise). This - essentially Carnapian strategy would, in Kaila's view, be not empiricist at all. It would rather amount to an empirically empty (almost 'scholastic') formalism. On the other hand, Kaila goes not so far as to embrace the idiom of speculative metaphysics. As he stresses in his recently translated Inhimillinen tieto (published first in 1939), "the assumption that 'behind' experience there is another, intellectually more perfect world" (Kaila [1939] 2014, p. 29) is empirically not confirmed and hopelessly "imprecise" (ibid.). Thus it is empirical scientific realism rather than metaphysical realism by which the Kailaian point of view is driven. Or, as Niiniluoto has once put it:

Kaila had high respect for the exact philosophical method of the Vienna Circle. Therefore, he strived for a careful formulation of the realism issue, one that would satisfy the critical demands of the new logical empiricism. But it was clear that Kaila - the philosopher of nature who wanted to solve the riddle of reality - could not follow the "linguistic turn" of Analytical Philosophy: for him the deepest problems of philosophy concern reality rather than language. (Niiniluoto 1992, p. 103)

Kaila, who stood in close contact both to Reichenbach and to the members of the Vienna Circle (see Manninen 2012), grounded his approach to science on two major principles: the principle of testability (see esp. Kaila [1936] 1979, pp. 62-63) and the principle of invariance (see esp. Kaila [1941] 1979, pp. 149-162). While he characterized the first principle as the "principle of logical empiricism" ([1936] 1979, p. 62), the second principle served, as it were, as his criterion of reality. Accordingly, Kaila's point of view should be conceived of as a fourth variety of 'realistic claims in logical empiricism.' As such, it can be best characterized as being based on an 'invariantist' - directly science-related (and thus not metaphysically motivated) - argument. Hence it is, I claim, appropriate (and justified) to see in Kaila the most explicit proponent of a realistically inspired variant of logical empiricism.

In order to substantiate this contention, it is advisable to first have a short glimpse at Kaila's principle of testability. As he points out in his monograph On the Concept of Reality in Physical Science: Second Contribution to Logical Empiricism, first published in 1941, it is 
"measurement statements" by which the theoretical hypotheses of physics are empirically tested. Kaila writes:

$[\mathrm{T}]$ he principle of physical testability, which defines empirical statements as 'physical', states that the real content of any physical statement $[\ldots]$ consists in the set of measurement statements which are derivable from the statement (in connection with given data). A statement which does not have any such real content is by definition not a physical statement. This principle is implied by the requirement that the singular empirical statements of physics (the basic statements) be exclusively measurement statements. (Kaila [1941] 1979, p. 184)

Had Kaila in earlier writings demanded that theoretical statements be translatable into the language of observation (see Niiniluoto 2012, pp. 79-80), he now felt content with their being testable by executing measurements: "[T]he assumption of translatability is not necessary [...]; testability would suffice" (Kaila [1941] 1979, p. 143). Moreover, Kaila clearly saw the need for idealization in scientific theory construction and therefore contended that "no theory is decidable, verifiable or falsifiable, in the strict sense; there is decidability only in a certain 'relaxed' or 'weakened' sense; this, however, is testability” (ibid., p. 162).

Kaila's second principle, the principle of invariance, may be portrayed as the very core of his entire philosophical conception (see von Wright 1992, pp. 80-81). In a nutshell, this principle implies that whenever we talk about (both scientific and everyday) reality, we refer to 'invariances.' "There is knowledge only," Kaila maintains, "when some similarity, sameness, uniformity, analogy, in brief, some 'invariance' is found and given a name. In knowledge, we are always concerned with 'invariances' alone” (Kaila [1941] 1979, p. 131). As Kaila further points out, the discovery of invariances always goes along with the establishment of a certain structural identity (or isomorphism). In Kaila's own words:

[I]f one succeeds, e.g., in giving for some domain an account which is in some sense 'unified', then we have the discovery of an 'invariance'; some characteristic or other of higher or lover conceptual level will then have been shown to be invariant with respect to a permutation of the places of the domain. Likewise, e.g., in any formal analogy, structural identity, isomorphism between two different domains, there is also some logically or mathematically definable 'structure', e.g., an equation, that is invariant with respect to the interchange of these domains. (ibid, p. 151)

All of this amounts to a 'structural realist' account of science and scientific theory construction. According to Kaila, it is invariant structures that are captured and described by our best corroborated theories of physical reality. One can even go as far as to say that, for Kaila, 
physical reality is nothing but invariant structures. "The 'real'," Kaila declares, "is what is in some respect (relatively) invariant" (ibid., p. 185). It is relatively invariant because, in Kaila's view, we have, according to the respective degree of invariance, different layers of reality. Thus Kaila provides us with some sort of ontological hierarchy which extends from perceptual reality to (thing-like) everyday reality and eventually to what is called by him 'physicoscientific reality.' Or, in his own words:

The physical reality of everyday is a system of invariances of experience, in which a large part of the phenomena is adjudged as 'illusion' and eliminated. Physico-scientific reality is the system of higher invariances of everyday reality, in which again a large part of the latter reality is adjudged as 'illusion' and eliminated. [...] [P]hysico-scientific reality, which is represented by the system of real-descriptions, is in logical respects the highest reality we can attain. (ibid.)

So much should have become clear by now: Kaila's invariantism delivers an independent, non-linguistic, argument for a scientifically realist articulation of the logical empiricist program. According to him, invariance is not inherent in our language but an immanent feature of physical reality (of which our language systems are a part of). Conceived that way, Kaila's invariantist alternative implies that "physical and scientific objects are objective, independent of us and our perceptions" (Niiniluoto 1992, p. 113). Yet this does not imply that Kaila fell back into the idiom of speculative metaphysics. To be sure, the 'best' invariances we have in science (such as Noether's theorem in classical mathematical physics, comparable invariant theorems in quantum mechanics, etc.) are formulated in mathematical languages (governed by certain logical and non-logical rules). Therefore Kaila's realistic, non-linguistic, interpretation of the invariance concept might appear to be too far-reaching in terms of 'ontological commitment' (at least from an empiricist point of view). However, in order to account for the empirical content of the invariance concept (and its various applications) the realistic interpretation is the only plausible way to go, since invariances are nothing that can be directly observed. On the other hand, it cannot be denied that by formulating principles of invariance something about empirical reality is intended to be conveyed. In short, Kaila's invariantist argument is sound, provided we accept its status as an answer to the question of how the mathematized language of theoretical physics can be empirically interpreted.

However, it still remains to be shown how the principle of testability and the principle of invariance are tied to each other. Concerns of space prevent an extended discussion of this point in this investigation, but suffice it to note that Kaila's theory of measurement is destined 
to achieve the desired solution. According to this (thoroughly anti-conventionalist) theory, it is metrical relations that are subject of the application of the principle of testability. Metrical relations, in turn, are the building blocks of Kaila's invariantist ontology. They are what, in the first place, render measurement possible and, thus, are to be seen as "elementary facts which must be present independently of measurement" (Kaila [1941] 1979, p. 200; my emphasis). Thus according to Kaila, the (physically) real is what can be measured, and what can be measured are invariant systems of relations, viz. structures. Consequently, his invariantist approach comes very close to structural realism. The following passage from his book on human knowledge might serve to corroborate this claim:

Kant argued that knowledge pertains to appearances only and not to 'things-in-themselves'. And yet he clearly thought that there is an isomorphic relation between appearances and things-in-themselves. That is to say, appearances are representations of things-in-themselves; they share a structure, although, according to Kant, that structure is realized in material that is completely different in the two cases.

We can see therefore that it is wrong to say that we know nothing of things-inthemselves: after all, we do know their structure. And if the extreme view turned out to be correct that our knowledge is in the last analysis just a matter of mere representation, we would have to say that we know just as much about things-in-themselves as we do about appearances. (Kaila [1939] 2014, p. 14)

Interestingly enough, in the footnote pertaining to this passage Kaila refers the reader to Bertrand Russell's (structuralist) Introduction to Mathematical Philosophy from 1919 (see, in this connection, especially Russell 1919, p. 61). At any rate, for Kaila, the structure of Kantian things-in-themselves is knowable because invariant structures are what can be measured.

\section{Concluding Remarks}

By way of conclusion, it is instructive to note that the four described varieties of realistic claims in logical empiricism evolved from a rather defensive 'empirical realist' account of science and nature (Carnap and Schlick) to a significantly more offensive articulation of realistic intuitions within the realm of semantics. Reichenbach's probabilistic, Feigl's pragmatic and Hempel's indispensability argument have to be seen against this background. Yet, neither of these arguments is really persuasive. The invariantist argument delivered by Kaila, on the other hand, is more promising. The finally effected fusion of logical empiricist (principle of testability) and structural realist (principle of invariance) components has the potential to 
stake out a middle path between so-called 'epistemic' structural realism and so-called 'ontic' structural realism (for the details of this distinction, see Ladyman 1998). The principle implications of the resulting variant of a 'metrological' structural realism have been indicated elsewhere (see Neuber 2012, esp. pp. 374-379); its full systematic exploitation, though, remains the subject of future enquiry. However, it has hopefully become clear in the present paper that Kaila's 'invariantist alternative' must be appreciated as a highly original contribution to the logical empiricist movement and therefore deserves more attention than it has received so far.

\section{Acknowledgments}

The author would like to thank Joseph J. Kominkiewicz and two anonymous referees who made suggestions that improved this paper significantly.

\section{References}

Boyd, R. (1982). Scientific Realism and Naturalistic Epistemology. In: PSA: Proceedings of the Biennial Meeting of the Philosophy of Science Association, 1980, vol. 2, 613-662.

Boyd, R. (1983). The Current Status of the Issue of Scientific Realism. In: Erkenntnis, 19, 4590.

Carnap, R. (1968 [1928a]). The Logical Structure of the World, translated by R.A. George. London: Routledge.

Carnap, R. (1968 [1928b]). Pseudoproblems in Philosophy, translated by R.A. George. London: Routledge.

Carnap, R. (1956 [1950]). Empiricism, Semantics, and Ontology. In: Meaning and Necessity, $2^{\text {nd }}$ edition, with Supplementary Essays (pp. 205-221). Chicago: The University of Chicago Press.

Creath, R. (2014). (Anti-)Metaphysics in the Thirties: And Why Should Anyone Care Now? In: M.C. Galavotti, E. Nemeth \& F. Stadler (Eds.), European Philosophy of Science - Philos- 
ophy of Science in Europe and the Viennese Heritage (pp.67-76). Dordrecht, Heidelberg, New York, London: Springer.

Feigl, H. (1950a). Existential Hypotheses. In: Philosophy of Science, 17, 35-62.

Feigl, H. (1950b). Logical Reconstruction, Realism and Pure Semiotic. In: Philosophy of Science, 17, 186-195.

Friedman, M. (1999). Reconsidering Logical Positivism. Cambridge: Cambridge University Press.

Friedman, M. (2007). The Aufbau and the Rejection of Metaphysics. In: M. Friedman \& R. Creath (Eds.), The Cambridge Companion to Carnap (pp. 129-152). Cambridge: Cambridge University Press.

Hempel, C.G. (1950). A Note on Semantic Realism. In: Philosophy of Science, 17, 169-173.

Hempel, C.G. (1958). The Theoretician's Dilemma: A Study in the Logic of Theory Construction. In: H. Feigl et al. (Eds.), Minnesota Studies in the Philosophy of Science, vol. II (pp. 37-98). Minneapolis: University of Minnesota Press.

Kaila, E. (1979 [1930]). Logistic Neopositivism: A Critical Study. In: Eino Kaila: Reality and Experience. Four Philosophical Essays, edited by R.S. Cohen (pp. 1-58). Dordrecht: Reidel.

Kaila, E. (1979 [1936]). On the System of the Concepts of Reality. A Contribution to Logical Empiricism. In: Eino Kaila: Reality and Experience. Four Philosophical Essays, edited by R.S. Cohen (pp. 59-125). Dordrecht: Reidel.

Kaila, E. (1979 [1941]). On the Concept of Reality in Physical Science. Second Contribution to Logical Empiricism. In: Eino Kaila: Reality and Experience. Four Philosophical Essays, edited by R.S. Cohen (pp. 126-258). Dordrecht: Reidel.

Kaila, E. (2014 [1939]). Human Knowledge: A Classic Statement of Logical Empiricism, translated by A. Korhonen, edited by J. Manninen, I. Niiniluoto \& G.A. Reisch. Chicago: Open Court.

Ladyman, J. (1998). What is Structural Realism? In: Studies in the History and Philosophy of Science, 29, 409-424. 
Manninen, J. (2012). Eino Kaila in Carnap's Circle. In: I. Niiniluoto \& S. Pihlström (Eds.), Reappraisals of Eino Kaila's Philosophy (pp. 9-52). Helsinki: Societas Philosophica Fennica.

Nagel, E. (1938). Review of Reichenbach's Experience and Prediction. In: The Journal of Philosophy, 35, 270-272.

Nagel, E. (1939). Probability and the Theory of Knowledge. In: Philosophy of Science, 6, 212-253.

Nagel, E. (1950). A Note on Semantic Realism. In: Philosophy of Science, 17, 169-181.

Neuber, M. (2011). Feigl’s ‘Scientific Realism’. In: Philosophy of Science, 78, 165-183.

Neuber, M. (2012). Invariance, Structure, Measurement - Eino Kaila and the History of Logical Empiricism. In: Theoria, 78, 358-383.

Neuber, M. (2014). Is Logical Empiricism Compatible with Scientific Realism?. In: M.C. Galavotti, E. Nemeth \& F. Stadler (Eds.), European Philosophy of Science - Philosophy of Science in Europe and the Viennese Heritage (pp.247-262). Dordrecht, Heidelberg, New York, London: Springer.

Niiniluoto, I. (1992). Eino Kaila and Scientific Realism. In: I. Niiniluoto, M. Sintonen \& G.H. von Wright (Eds.), Eino Kaila and Logical Empiricism (pp. 102-116). Helsinki: Societas Philosophica Fennica.

Niiniluoto, I. (1996). Critical Scientific Realism. Oxford: Oxford University Press.

Niiniluoto, I. (2012). Eino Kaila's Critique of Metaphysics. In: I. Niiniluoto \& S. Pihlström (Eds.), Reappraisals of Eino Kaila's Philosophy (pp. 71-89). Helsinki: Societas Philosophica Fennica.

Psillos, S. (1999). Scientific Realism: How Science Tracks Truth. London, New York: Routledge.

Psillos, S. (2011a). On Reichenbach's Argument for Scientific Realism. In: Synthese, 181, 23 40.

Psillos, S. (2011b). Choosing the Realist Framework. In: Synthese, 180, 301-316. 
Putnam, H. (2001). Hans Reichenbach: Realist and Verificationist. In: J. Floyd \& Sanford Shieh (Eds.), Future Past: The Analytic Tradition in Twentieth-Century Philosophy (pp. 277287). Oxford: Oxford University Press.

Reichenbach, H. (1938). Experience and Prediction: An Analysis oft he Foundations and the Structure of Knowledge. Chicago: The University of Chicago Press.

Reichenbach, H. (1956). The Direction of Time, edited by M. Reichenbach. Berkeley, Los Angeles: University of California Press.

Russell, B. (1919). Introduction to Mathematical Philosophy. London: George Allen and Unwin.

Salmon, W. (1984). Scientific Explanation and the Causal Structure of the World. Princeton: Princeton University Press.

Salmon, W. (1999a). Ornithology in a Cubical World: Reichenbach on Scientific Realism. In: D. Greenberger, R.L. Wolfgang \& A. Zeilinger (Eds.), Epistemological and Experimental Perspectives on Quantum Physics (pp. 305-315). Dordrecht: Kluwer.

Salmon, W. (1999b). The Spirit of Logical Empiricism: Carl G. Hempel's Role in TwentiethCentury Philosophy of Science. In: Philosophy of Science, 66, 333-350.

Salmon, W. (2005). Scientific Realism in the Empiricist Tradition. In: Reality and Rationality, edited by P. Dowe \& M.H. Salmon (pp. 19-30). Oxford: Oxford University Press.

Schlick, M. (1979 [1932]). Positivism and Realism. In: Philosophical Papers, vol. 2, edited by H.L. Mulder and B. van de Velde-Schlick (pp. 259-284). Dordrecht: Reidel.

Sober, E. (2011). Reichenbach's Cubical Universe and the Problem of the External World. In: Synthese, 181, 3-21.

Stadler, F. (2001). The Vienna Circle: Studies in the Origins, Development, and Influences of Logical Empiricism. Vienna: Springer.

Uebel, T. (2007) Empiricism at the Crossroads: The Vienna Circle's Protocol-Sentence Debate. Chicago and LaSalle, Illinois: Open Court. 
Von Wright, G.H. (1992). Eino Kaila’s Monism. In: I. Niiniluoto, M. Sintonen \& G.H. von Wright (Eds.), Eino Kaila and Logical Empiricism (pp. 71-91). Helsinki: Societas Philosophica Fennica. 